\title{
Evidence Production in Merger Control: The Role of Remedies
}

\author{
Markus Dertwinkel-Kalt ${ }^{1}$ (D) $\cdot$ Christian Wey $^{2}$
}

Accepted: 24 February 2021 / Published online: 10 March 2021

(c) The Author(s) 2021

\begin{abstract}
We analyze evidence production in merger control as a delegation problem in an inquisitorial competition policy system. The antitrust agency's incentives to produce evidence on the efficiency of a merger proposal depend critically on its action set. Allowing for a compromising remedy solution reduces information acquisition incentives, and could therefore reduce consumer welfare. The effort-frustrating effect of the remedy solution can be eliminated if a remedy solution can be implemented only after evidence on the efficiency of a merger proposal has been produced.
\end{abstract}

Keywords Merger remedies $\cdot$ Merger control $\cdot$ Antitrust

JEL Classification $\mathrm{L} 13 \cdot \mathrm{L} 40 \cdot \mathrm{K} 21$

"Overall [...] remedies have been used too often, too widely, too optimistically, and perhaps even strategically to the extent that they represent methods of avoiding challenging mergers but wishing to appear to be taking some action.

This overuse of remedies [...] must be reversed in order to reverse the unfortunate evolution of merger policy into remedy policy.” —John Kwoka (2020: 99-100)

\footnotetext{
For helpful comments and suggestions we thank the editor, Lawrence J. White, two anonymous referees, as well as Andreea Cosnita-Langlais, Catarina Marvao, Monika Schnitzer, Christoph Schottmüller, Lars Sorgard, Deszö Szalay, and audiences at the EEA (Geneva), IIOC (Philadelphia), CRESSE conference (Rhodes), EARIE conference (Milan), BECCLE conference (Bergen), Verein für Socialpolitik annual conference (Münster), Industrial Economics committee meeting (Berlin), Heinrich-Heine University Düsseldorf, Norwegian School of Economics (Bergen), Würzburg University, and Paris-West/Nanterre University.

Markus Dertwinkel-Kalt

markus.dertwinkel-kalt@uni-konstanz.de

Christian Wey

wey@dice.hhu.de

1 University of Konstanz, Universitätsstr. 10, 78464 Constance, Germany

2 HHU Düsseldorf, Düsseldorf Institute for Competition Economics (DICE), Universitätsstr. 1, 40213 Düsseldorf, Germany
} 


\section{Introduction}

In a landmark decision in May 2020, the General Court of the European Union annulled the decision of the European Commission to block the acquisition of Telefonica UK by Hutchison 3G UK: The Court stated that the Commission failed to prove that this acquisition would have harmed competition. ${ }^{1}$ This case highlights the policy relevance of the question how antitrust agencies produce evidence, and how the incentives to produce evidence in merger control can be enhanced.

We analyze evidence production in merger control as a delegation problem in an inquisitorial competition system. Depending on its ex-ante uncertain efficiency type, a merger proposal can be anti- or pro-competitive: consumer welfare reducing or increasing. A principal-agent problem between the legislator-whose objective is to maximize consumer welfare-and the antitrust agency-whose objective is consumer surplus minus effort costs_-arises from the fact that the agency's investigative effort in a merger case is non-contractible.

We investigate how different action sets of the agency affect its incentives to exert effort and acquire information on the efficiency type of a proposed merger. We compare the case (1) in which the agency can either approve or prohibit the merger altogether with the case (2) where a merger can also be cleared conditionally on the basis of a remedy solution. Throughout our analysis we take the remedy solution as a compromising choice that is optimal from an ex ante perspective: whenever only the a priori information on the merger's efficiency type is available.

Our main contribution is to show that allowing for remedial solutions deteriorates incentives for the agency. As the remedy solution represents a compromising choice and thereby the negative effect of a false extreme decision, allowing for it reduces the agency's incentives to obtain information on the merger's efficiency type. Altogether, the availability of the remedy solution reduces the agency's effort provision when compared to a no-remedy regime that forces the agency to either to approve or to prohibit the merger.

In contrast, in a scenario in which only extreme options are implementable, a false decision bears the risk of making a wrong decision with strong negative consequences. Therefore, in the absence of the remedy solution, the agency acquires more information in order to avoid such negative consequences. Thus, it can be desirable overall for the legislator to remove the remedy solution from the agency's choice set. $^{2}$

Finally, we analyze "evidence-based remedies" whereby a remedy solution can be implemented only if the agency has gathered and evaluated information that supports the ex-post optimality of the remedy decision. This leads to higher information (and higher consumer welfare) levels than in the case where remedies cannot

\footnotetext{
${ }^{1}$ See the ruling of the General Court in Case T-399/16 at https://curia.europa.eu/jcms/upload/docs/appli cation/pdf/2020-05/cp200065en.pdf.

${ }^{2}$ This result has to be qualified when the remedy solution can also be ex post efficient. Then, information acquisition incentives increase in a system with a remedy option the more likely it is that the remedial solution is the ex post optimal choice.
} 
be implemented. As a consequence, requiring evidence for the remedial solution is always weakly preferred over a no-remedy regime.

\section{The Model}

The model that we present in the following builds on two models that have been proposed in the literature: Cosnita-Langlais and Tropeano (2012), and Szalay (2005). First, our merger model follows the reduced-form model proposed by Cosnita-Langlais and Tropeano (2012), whereby different merger types can be uniquely characterized by an efficiency parameter. This efficiency parameter represents the net effect of the usual trade-off that goes along with a merger: On the one hand, we assume that the merger has the potential-if not counteracted by efficiencies and/or a remedy - to yield market power for the post-merger firm, which generates an upward pricing pressure. On the other hand, a merger may decrease production costs, which generates a downward price pressure. Mergers differ in the efficiencies that they generate (see Besanko and Spulber 1993), and the higher is the efficiency, the stronger is the second effect relative to the first one; and the more desirable is a merger from a consumer-surplus point of view.

To learn about a merger's efficiency type, the antitrust agency has to invest effort. ${ }^{3}$ To model the principal-agent problem between the legislator and the antitrust agency as well as the agency's information acquisition problem, we employ the quite general model by Szalay (2005), who examines a principal-agent model in which the agent collects information and then chooses a verifiable action. The agent's effort is not contractible and the principal cannot design an incentive compatible con tract based on ex post outcomes. The critical step in this analysis is to focus on the agent's incentives as a result of the composition of her choice set. It is shown that it can be optimal to remove the intermediate choices from the agent's action set to increase her incentives to acquire information. The model that we present in the following basically applies the model by Szalay (2005) to antitrust.

We now formally introduce our model: In our inquisitorial system, the legislator delegates the enforcement of merger control (evidence production and the final decision making) to an agency. ${ }^{4}$ Their objectives are aligned in the following sense. The objective of the agency is consumer welfare, but the agency also takes its effort costs for information acquisition into account and therefore maximizes consumer surplus minus its information costs. 5

\footnotetext{
3 We thereby abstract from two other crucial issues on which an antitrust agency needs to collect and evaluate evidence: On the one hand, it has to delineate the relevant market for the merging firms and has to evaluate the possibility that the firm could exercise market power within that delineated market; and, on the other hand, it has to evaluate whether a proposed remedy will cure the problem. We come back to this issue in the Conclusion.

4 This definition of an inquisitorial system follows, for instance, the definition given by Dewatripont and Tirole (1999) and applies, as delineated by Neven (2006), to merger control in the European Union.

5 It is a common assumption that bureaucrats are intrinsically motivated to serve the principal's objectives (Besley and Ghatak 2005; Prendergast 2007). Long-run motivation of the bureaucrats may also be
} 
Mergers differ in the efficiencies, $e$, that they generate. The distribution of efficiencies is given by the density function $f(e)$ on the interval $e \in[\underline{e}, \bar{e}]$, where $\underline{e}$ denotes the lowest and $\bar{e}$ the highest possible efficiency level. The prior distribution of efficiencies is common knowledge, while the specific efficiency level of a particular merger is the private information of the merging firms. The agency can acquire information on a merger's efficiency level by exerting costly effort to observe the true efficiency type with probability $\beta \in[0,1]$. If the agency chooses a particular value $\beta$, it learns the true efficiency type with probability $\beta$ and does not obtain any information on the merger type with counter probability $1-\beta .^{6}$ In case the merger type is not known, the agency will use the distribution of efficiencies (namely, $f(e)$ ) to determine the ex-ante optimal action, and will implement this.

Costs for information acquisition are given by $C(\beta)$, which fulfills the Inada conditions $C(0)=0, C^{\prime}(\beta)>0, C^{\prime \prime}(\beta)>0, \lim _{\beta \rightarrow 1} C(\beta)=+\infty$. The Inada conditions guarantee us an inner solution to the information-acquisition problem of the agency.

We investigate the agency's choices of $\beta$ under two regimes: NR (no-remedy regime) and $R$ (remedy regime). Under $N R$, the agency can only approve or prohibit the merger altogether. Under regime $R$, the agency can also condition its approval on a remedy solution. We assume that a unique remedy exists for every merger proposal, and that the implementation of this remedy does not render a proposed merger unprofitable for the proposing firms. ${ }^{7}$

Let $X$ indicate the agency's merger decision, $X \in\{M, N, R\}$, which can be: an approval $(X=M)$; a prohibition $(X=N)$; or an approval conditional on a remedy $(X=R)$. Given a merger of a certain efficiency type $e$, let $W^{X}(e)$ denote the change in consumer welfare when the agency adopts decision $X$. The expected change of consumer welfare if decision $X$ is adopted is given by $\bar{W}^{X}=\int_{\underline{e}}^{\bar{e}} W^{X}(e) f(e) d e$. If a merger proposal is prohibited, consumer welfare does not change, so that $\bar{W}^{N}=0$ holds.

We impose the following assumptions on the pre- and the post-merger market outcomes, which are in line with models that analyze structural remedies in oligopolistic markets such as Cabral (2003), Vergé (2010), Vasconcelos (2010), and Dertwinkel-Kalt and Wey (2016):

\footnotetext{
Footnote 5 (continued)

provided by the fear of the restructuring of their institution in the case of its failure. Direct financial incentives, however, are almost unfeasible as bureaucrats are not paid according to their performance.

${ }^{6}$ For brevity and following Szalay (2005), we consider a setting in which gathered information is always correct; but it is straightforward to show that our results also hold if acquired information is false with some probability.

${ }^{7}$ In the case of structural remedies only a specific business unit or production plant may qualify as a remedial divestiture (Vasconcelos 2010). Moreover, legal requirements reduce the set of possible remedies. For example, the remedy must be easily applicable and a divestiture qualifies as a potential remedy only if it is a "viable business" that can "operate on a stand-alone basis" (EC 2008). Thus, wider packages may be required in order to satisfy viability (Motta et al. 2007; Davies and Lyons 2007). In the case of vertical mergers and behavioral remedies, standard obligations not to foreclose outsiders and to (positively) supply them at a reasonable price quite naturally arises as a remedy for a merger proposal.
} 


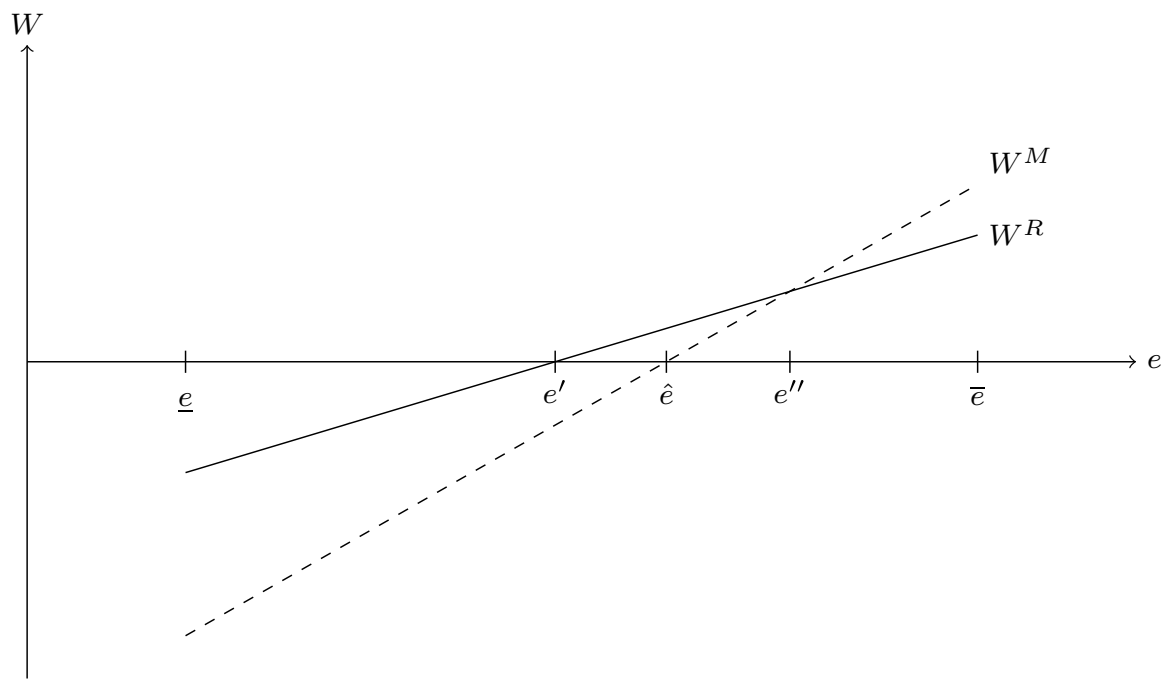

Fig. 1 Thresholds concerning $\mathrm{W}$ for a continuous distribution of merger efficiencies

A1: Consumer welfare $W^{X}(e)$ is continuous and strictly monotonically increasing in e for all $X \in\{M, R\}$. Let $W^{M}(\underline{e})<0$ and $W^{M}(\bar{e})>0$. Furthermore, assume that

$$
\frac{\mathrm{d} W^{M}(e)}{\mathrm{d} e}>\frac{\mathrm{d} W^{R}(e)}{\mathrm{d} e}>0 .
$$

Condition (1) is intuitive: The (positive or negative) effect of a merger's efficiency affects consumer welfare to a larger degree if the merger is fully implemented than if its effects are mitigated by the remedy solution. This setting is illustrated in Fig. 1.

From Assumption A1 it follows that the function $W^{M}(e)$ has at most one zero. $W^{R}(e)$ has also at most one zero and intersects with $W^{M}(e)$ at most once. Without loss of generality, we assume that all three points of intersection exist, ${ }^{8}$ and are denoted by $e^{\prime}$ ( $\operatorname{such}$ that $\left.W^{R}(e)=0\right), e^{\prime \prime}\left(\operatorname{such}\right.$ that $\left.W^{R}(e)=W^{M}(e)\right)$ and $\hat{e}$ ( $\operatorname{such}$ that $\left.W^{M}(e)=0\right)$, respectively. Let $e_{1}:=\min \left\{e^{\prime}, \hat{e}\right\}$ and $e_{2}:=\max \left\{e^{\prime \prime}, \hat{e}\right\}$. For brevity, we assume that there is zero probability mass on the threshold values $e^{\prime}, e^{\prime \prime}$ and $\hat{e}$.

From a consumer welfare perspective: A prohibition of the merger is optimal for $\underline{e}<e<e_{1}$; remedies are optimal for $e_{1}<e<e_{2}$; and a full merger is optimal for $\bar{e}_{2}<e<\bar{e}$. Note that these intervals may be empty, for instance, if $e_{2}<e_{1}$.

A2: Ex ante-based on the distribution of efficiencies - an approval conditional on a remedy is preferred from a consumer welfare perspective: $\bar{W}^{R}>\max \left\{\bar{W}^{M}, 0\right\}$.

According to A2, we invoke a "remedy-favoring assumption": Ex ante-before the acquisition of costly evidence-it is optimal to approve any merger proposal that is conditional on a remedy. This mirrors our motivation to interpret the decision to

\footnotetext{
8 We impose this assumption for notational ease while it does not compromise our analysis.
} 
approve a merger that is conditional on remedies as an intermediate option which is optimal if no information is available (as in Szalay 2005). In contrast, extreme decisions such as an unconditional approval or the outright prohibition of the merger bear the risk of making a "large" mistake with substantial consumer welfare losses. Hence, in the absence of any additional information, the remedy option represents a relatively "safe" choice

We distinguish between two types of remedy regimes: First, we analyze the "standard" remedy regime as described above; and second we examine "evidencebased" remedies. In the former case, a remedial solution can be implemented without any empirical justification, so that its use will be decided only in terms of expected values. In the latter case, a remedial solution can be implemented only when there is hard evidence that the remedy is indeed optimal; that is, information must be gathered and evaluated that supports the optimality of the remedy decision.

\section{Analysis}

\subsection{Standard Remedy Regime}

We analyze the following game: In stage zero, a merger is proposed. ${ }^{9}$ In the first stage, the legislator decides on the agency's action space: The legislator decides whether remedies are feasible (regime $R$ ) or not (regime $N R$ ). In the second stage, the agency decides on the quality of information $\beta$ it acquires. Finally, in the third stage, the agency makes its final judgment on the merger proposal. If it has not learned the precise efficiency type (which happens with probability $1-\beta$ ), it decides on what is feasible and ex-ante optimal.

We solve this game via backward induction: The agency's decision in the third stage depends on the availability of the remedial option and the information $\beta$ that it has acquired in the second stage. Suppose regime $R$ applies: If the agency holds information on the merger's type, then it decides according to the following decision rule: A merger of type $e \in\left[e_{2}, \bar{e}\right]$ is approved; a merger of type $e \in\left[e_{1}, e_{2}\right]$ is approved with a remedy; and a merger of type $e \in\left[\underline{e}, e_{1}\right]$ is prohibited. Thus, with information on the efficiency of the merger at hand, the agency always implements the (ex post) consumer welfare-maximizing solution. If, to the contrary, the agency does not hold any information, then the remedy is implemented due to our remedyfavoring assumption A2.

Next, suppose regime $N R$ applies: Thus, if no information is held ${ }_{M}$ then the merger is prohibited if $\max \left\{0, \widehat{W}^{M}\right\}=0$; and it is approved if $\max \left\{0, \vec{W}^{M}\right\}=\vec{W}^{M}$.

\footnotetext{
9 The merger proposal happens in stage zero, before the actual game, because it does not represent a strategic decision. As in Lagerlöf and Heidhues (2005), the population of submitted mergers is always the same. This is also a natural result of our model as a merger proposal is always costless and any merger implementation (also if it is conditioned on remedies) is profitable for the merging firms. We thereby abstract from how the enforcement regime could affect the population of submitted mergers, as analyzed in, e.g., Sorgard (2009), Seldeslachts et al. (2009), and Clougherty et al. (2016).
} 
If information is held, a merger of type $e \in[\hat{e}, \bar{e}]$ is fully approved; and a merger of type $e \in[\underline{e}, \hat{e}]$ is prohibited.

In the second stage, the agency chooses the level of information $\beta \in[0,1]$. Under regime $R$, the equilibrium level of information acquisition $\beta_{R}$ is given by the maximization of

$$
\begin{aligned}
& \beta\left(\int_{\underline{e}}^{e_{1}} f(e) W^{N}(e) d e+\int_{e_{1}}^{e_{2}} f(e) W^{R}(e) d e+\int_{e_{2}}^{\bar{e}} f(e) W^{M}(e) d e\right) \\
& \quad+(1-\beta) \bar{W}^{R}-C(\beta) .
\end{aligned}
$$

Under regime $N R$, the equilibrium is given by the maximization of

$$
\beta\left(\int_{\underline{e}}^{\hat{e}} f(e) W^{N}(e) d e+\int_{\hat{e}}^{\bar{e}} f(e) W^{M}(e) d e\right)+(1-\beta) \max \left\{0, \bar{W}^{M}\right\}-C(\beta) .
$$

With $W^{N}(e)=0$ the optimal information levels $\beta_{N R}^{*}$ and $\beta_{R}^{*}$ follow from the first-order conditions

$$
\begin{gathered}
\int_{e_{1}}^{e_{2}} f(e) W^{R}(e) d e+\int_{e_{2}}^{\bar{e}} f(e) W^{M}(e) d e-\bar{W}^{R} \stackrel{!}{=} C^{\prime}\left(\beta_{R}^{*}\right), \text { and } \\
\int_{\hat{e}}^{\bar{e}} f(e) W^{M}(e) d e-\max \left\{0, \bar{W}^{M}\right\} \stackrel{!}{=} C^{\prime}\left(\beta_{N R}^{*}\right),
\end{gathered}
$$

respectively.

To focus our analysis on the agency's effort choice, we now maintain the assumption that the remedial option is never the ex post optimal choice.

A3: Ex post the remedial option is never optimal: $e_{1}=e_{2}=\hat{e}$.

We then obtain the following proposition.

Proposition 1 Under Assumption A3, the agency acquires a higher information level under regime NR than under regime R. Expected consumer surplus is higher under NR if and only if the higher level of information is sufficient to counterbalance the detrimental effects of the remedy's removal in the no-information scenario: if

$$
\begin{aligned}
& \underbrace{\left(\beta_{N R}^{*}-\beta_{R}^{*}\right) \cdot \int_{\hat{e}}^{\bar{e}} f(e) W^{M}(e) d e}_{\text {positive effect of } N R \text { due to more information }} \\
& >\underbrace{\left(1-\beta_{R}^{*}\right) \cdot \bar{W}^{R}-\left(1-\beta_{N R}^{*}\right) \cdot \max \left\{\bar{W}^{M}, 0\right\}}_{\text {negative effect of } N R \text { when no information available }} .
\end{aligned}
$$

Proof Comparing (4) and (5) under A3 immediately yields that $\beta_{N R}^{*}>\beta_{R}^{*}$. Formula (6) follows from rearranging (2) and (3). 
If remedies are not ex post optimal for any merger proposal, then the removal of the intermediate option increases the agency's incentives to acquire information. This result is driven by the following intuition: If remedies are feasible, it may be optimal for the agency to exert very little effort and to apply remedies since the potential error that accompanies this decision is limited. If, however, remedies are not feasible, then the potential error that is associated with an extreme decision might be so high that exerting more effort-acquiring better information-is optimal for the agency. With better information at hand, the agency limits the potentially high costs that are associated with an erroneous decision.

Besides this positive incentive effect of a removal of the remedy option, the removal also creates a real cost because the remedy is optimal on average: in the absence of concrete information with respect to a proposal's type. By acquiring more information, remedies become less important since the range where they are optimal - the number of no-information scenarios-shrinks.

Whether or not the additionally acquired information also gives rise to an increase in consumer surplus depends on the interplay between consumer welfare losses that are due to the removal of remedies and the gains in consumer welfare due to the higher information acquisition level. In equilibrium, the positive surplus effect of an improved information level may overcompensate the welfare losses that result from the removal of the remedial option. In that case, the legislator optimally decides to remove the remedy option from the agency's action space.

The optimality of the extreme option regime $N R$ depends on the exact shape of the information cost function $C$. Regime $N R$ is most likely to dominate regime $R$ from a consumer perspective if the difference in information acquisition is sufficiently high between the regimes-which is the case if information acquisitions costs are at an intermediate level: $C$ is neither too steep nor too flat. Then, to spur the information acquisition incentives of the agency and thereby to increase consumer welfare, the legislator finds the removal of the remedial option attractive.

Note that Proposition 1 holds qualitatively not only when remedies are not ex post optimal, but also if the range where remedies are ex post optimal is not too large.

That an inquisitorial law enforcement system has insufficient incentives to produce evidence has been also shown in other setups: In Dewatripont and Tirole (1999) the inquisitorial system decides too often for an extreme option which is in stark contrast to our model. That difference is due to their key assumption that the obtained information can be conflicting. The inquisitorial authority has insufficient incentives to gather a second piece of information that might stand in conflict with the initially obtained information. In our setup, in contrast, the agency already has too few incentives to obtain the very first piece of information with the relatively safe, intermediate option at hand. 


\subsection{Remedies with "Hard Evidence"}

We now suppose that the legislator can opt for a third regime-in addition to approval/denial - in which the remedy option can be implemented only when the agency has obtained evidence as to the remedy's optimality. Let us denote this third regime by $R^{S}$ : In this case, a remedy cannot be applied if no information on the exact merger type has been acquired, so that it cannot be used as an intermediate option. Rather, the agency must gather information and persuasively argue that the remedial solution is indeed optimal if it wants to implement it. ${ }^{10}$

While under regime $N R$ the agency chooses $\beta_{N R}$ in order to maximize Condition (3), under regime $R^{S}$ it chooses $\beta_{R^{s}}$ in order to maximize

$$
\begin{aligned}
& \beta\left(\int_{\underline{e}}^{e_{1}} f(e) W^{N}(e) d e+\int_{e_{1}}^{e_{2}} f(e) W^{R}(e) d e+\int_{e_{2}}^{\bar{e}} f(e) W^{M}(e) d e\right) \\
& +(1-\beta) \max \left\{0, \bar{W}^{M}\right\}-C(\beta) .
\end{aligned}
$$

Note that the equilibrium information level according to (7) is always weakly higher under the evidence-based remedy regime than under a no-remedy regime: $\beta_{R^{s}}^{*} \geq \beta_{N R}^{*}$ holds, as information becomes more valuable. In fact, should the agency discover that the remedy is the optimal option, it can implement it under regime $R^{S}$ while it has to implement only a second-best option under regime $N R$. Consequently, the evidence-based remedy regime always induces both a weakly higher information level and a weakly higher consumer welfare level than under $N R$.

Corollary 1 If the legislator prefers regime NR over regime $R$, it prefers regime $R^{S}$ over regimes $R$ and $N R$.

The evidence-based remedy regime is appealing to the legislator for the following reasons: While this regime allows the implementation of the remedy if this represents the best available option, the regime eliminates the effort-frustrating effect of a remedy as a relatively safe intermediate option. Therefore, this regime always outperforms a no-remedy regime. Note that this point is not obvious: $R^{S}$ still has the disadvantage that it does not allow for the ex ante optimal option-the remedy-if no information is available. As we have shown, however, it can be optimal to remove the ex-ante optimal option in order to provide better incentives to the agency. If regime $N R$ outperforms regime $R$, then $R^{S}$ is the preferred regime of the legislator.

\footnotetext{
${ }^{10}$ In the decision EDP $v$ Commission the General court "ruled that if the notifying party submits commitments, the burden of showing that the concentration as amended by the commitments should be prohibited remains on the Commission" (Lindsay and Berridge 2012, FN 137).
} 


\section{Conclusion}

An inquisitorial enforcement system that allows for a remedial clearing of a merger is likely to suffer from an incentive problem as the agency's incentives to exert effort into information gathering and processing can be reduced by the intermediate option. The intermediate decision serves as a "safe" option that avoids the risks that are associated with extreme rulings; consequently, an extreme-option system may lead to greater evidence acquisition incentives and thus possibly higher consumer welfare. While this insight appears to be a simple one, it stands in contrast to the generally optimistic view on merger remedies as, for instance, expressed in the European legislation, which describes remedies as an effective way to restore competition (EC 2008, Article 22).

We thereby complement recent empirical studies that have taken a critical stance on remedies; these studies find that remedies have often failed to restore effective competition (Davies and Olczak 2010; Duso et al. 2011, 2013, Kwoka and Moss 2012, and Kwoka 2013, 2015, 2019). ${ }^{11}$ Complementary to this direct effect of failing to effectively restore competition, our analysis delineates a novel indirect effect that merger remedies could have: They could reduce the incentives of the antitrust agencies to invest in evidence production. Ultimately, this incentive effect could be so strong that an overall ban of the remedial option-a "no-remedy" regimeimproves merger control and consumer welfare. Notably, Kwoka (2020) concludes his extensive studies on the effectiveness of merger remedies with a similar statement (see our introductory quotation).

Finally, we have shown that merger control should unambiguously improve even beyond the "no-remedy" regime when a remedy solution is based on hard evidence that supports its optimality. Again, this finding is mirrored in the observation that remedy regulations have been tightened over time in the EU; in particular, the informational burden for remedies has been raised which is reflected in the publication of the "Revised Notice on Remedies" (see EC 2008, and Lindsay and Berridge 2012: 617).

Our model can be also interpreted in a different way, where information collection regards the merging firms' potential to exercise market power. On the one end are firms that operate in different relevant markets. In this case, a merger would correspond to a highly efficient merger in the current setup, which is unambiguously positive from a consumer perspective. On the other end are firms that operate in the very same relevant market. This case would correspond to the lowly-efficient merger in the current setup, that is unambiguously bad from a consumer perspective. Partly overlapping relevant markets would correspond to the case of intermediate efficiencies. Thus, our model could be re-interpreted for the case where the agency does not acquire information on efficiencies, but on the degree to which relevant markets overlap or market power can be exercised.

\footnotetext{
11 Kwoka (2015), for instance, shows in his meta analysis on US mergers that a large fraction of carefully studied mergers resulted in higher prices even when a remedy was imposed.
} 
Our analysis best applies when there is a unique remedy candidate, as in the case where a certain branch is to be divested off or not. In fact, however, it could take serious effort to determine what a good remedy could be. When this is the case, the effects we delineate are compromised. A model incorporating effort to find a good remedy would include an additional stage in which the agency invests effort to find a suitable remedy, and the agency either has a fixed budget to allocate across these two tasks, or it faces costs that are increasing in both tasks. Our effects of excessive remedy implementation would only survive in case finding the suitable remedy is not too costly.

Our model has also abstracted from the endogeneity of projects that are chosen for in-depth investigation and the associated problem of endogenous (opportunity) costs of effort within the authority. Considering the interplay between project choices and informational effort from a delegation perspective is an interesting venue for further research.

Funding Open Access funding enabled and organized by Projekt DEAL..

Open Access This article is licensed under a Creative Commons Attribution 4.0 International License, which permits use, sharing, adaptation, distribution and reproduction in any medium or format, as long as you give appropriate credit to the original author(s) and the source, provide a link to the Creative Commons licence, and indicate if changes were made. The images or other third party material in this article are included in the article's Creative Commons licence, unless indicated otherwise in a credit line to the material. If material is not included in the article's Creative Commons licence and your intended use is not permitted by statutory regulation or exceeds the permitted use, you will need to obtain permission directly from the copyright holder. To view a copy of this licence, visit http://creativecommons.org/licen ses/by/4.0/.

\section{References}

Besanko, D., \& Spulber, D. F. (1993). Contested mergers and equilibrium antitrust policy. Journal of Law, Economics, \& Organization, 9(1), 1-29.

Besley, T., \& Ghatak, M. (2005). Competition and incentives with motivated agents. American Economic Review, 95(3), 616-636.

Cabral, L. (2003). Horizontal mergers with free-entry: Why cost efficiencies may be a weak defense and asset sales a poor remedy. International Journal of Industrial Organization, 21(5), 607-623.

Clougherty, J. A., Duso, T., Lee, M., \& Seldeslachts, J. (2016). Effective European antitrust: Does EC merger policy generate deterrence? Economic Inquiry, 54(4), 1884-1903.

Cosnita-Langlais, A., \& Tropeano, J.-P. (2012). Do remedies affect the efficiency defense? An optimal merger-control analysis. International Journal of Industrial Organization, 30(1), 58-66.

Davies, S., \& Lyons, B. (2007). Mergers and merger remedies in the EU: Assessing the consequences for competition. Cheltenham: Edward Elgar.

Davies, S., \& Olczak, M. (2010). Assessing the efficacy of structural merger remedies: Choosing between theories of harm? Review of Industrial Organization, 37(2), 83-99.

Dertwinkel-Kalt, M., \& Wey, C. (2016). Merger remedies in oligopoly under a consumer welfare standard. Journal of Law, Economics, and Organization, 32(1), 150-179.

Dewatripont, M., \& Tirole, J. (1999). Advocates. Journal of Political Economy, 107(1), 1-39.

Duso, T., Gugler, K., \& Szücs, F. (2013). An empirical assessment of the 2004 EU Merger Policy Reform. Economic Journal, 123(572), F596-F619. 
Duso, T., Gugler, K., \& Yurtoglu, B. B. (2011). How effective is European merger control? European Economic Review, 55(7), 980-1006.

EC, (2008). Commission Notice on Remedies Acceptable under Council Regulation (EC) No 139/2004 and under Commission Regulation (EC) No 802/2004. Official Journal of the European Union, 2008/C 267/01, C267/1-C267/27.

Kwoka, J. (2013). Does merger control work? A retrospective on US enforcement actions and merger outcomes. Antitrust Law Journal, 78(3), 619-644.

Kwoka, J. (2015). Mergers, merger control, and remedies: A retrospective analysis of US policy. Cambridge, MA: MIT Press.

Kwoka, J. (2019). Masquerading as merger control: The U.S. Department of Justice settlement with Sprint and T-Mobile. AAI Working Paper.

Kwoka, J. (2020). Controlling mergers and market power: A program for reviving antitrust in America. Boston: Competition Policy International.

Kwoka, J. E., \& Moss, D. L. (2012). Behavioral merger remedies: Evaluation and implications for antitrust enforcement. Antitrust Bulletin, 57(4), 979-1011.

Lagerlöf, J., \& Heidhues, P. (2005). On the desirability of an efficiency defense in merger control. International Journal of Industrial Organization, 23(9-10), 803-827.

Lindsay, A., \& Berridge, A. (2012). The EU merger regulation: Substantive issues. London: Sweet and Maxwell.

Motta, M., Polo, M., \& Vasconcelos, H. (2007). Merger remedies in the European Union: An overview. Antitrust Bulletin, 52(3-4), 603-631.

Neven, D. (2006). Competition economics and antitrust in Europe. Economic Policy, 21(48), 741-791.

Prendergast, C. (2007). The motivation and bias of bureaucrats. American Economic Review, 97(1), $180-196$.

Seldeslachts, J., Clougherty, J. A., \& Barros, P. P. (2009). Settle for now but prevent for tomorrow: The deterrence effects of merger policy tools. Journal of Law and Economics, 52(3), 607-634.

Sorgard, L. (2009). Optimal merger policy: Enforcement vs. deterrence. Journal of Industrial Economics, $57(3), 438-456$.

Szalay, D. (2005). The economics of clear advice and extreme options. Review of Economic Studies, 72(4), 1173-1198.

Vasconcelos, H. (2010). Efficiency gains and structural remedies in merger control. Journal of Industrial Economics, 58(4), 742-766.

Vergé, T. (2010). Horizontal mergers, structural remedies, and consumer welfare in a Cournot oligopoly with assets. Journal of Industrial Economics, 58(4), 723-741.

Publisher's Note Springer Nature remains neutral with regard to jurisdictional claims in published maps and institutional affiliations. 